\title{
The relationship between the Type A behavior pattern, fear of death, and manifest anxiety
}

\author{
JAMES L. TRAMILL \\ Wichita State University, Wichita, Kansas \\ P. JEANNIE KLEINHAMMER-TRAMILL \\ Associated Colleges of Central Kansas, McPherson, Kansas
}

and

\author{
STEPHEN F. DAVIS, CHERRI S. PARKS, and DAVID ALEXANDER \\ Emporia State University, Emporia, Kansas
}

\begin{abstract}
Scores on the Death Anxiety Scale (DAS) and the unidimensional short form of the Taylor Manifest Anxiety Scale (TMAS) were evaluated as a function of personality type: A+, A-, B-, and B+. Type A+ personalities displayed higher DAS and TMAS scores than did the other personality types. Furthermore, it was found that females had higher scores than did males on both tests.
\end{abstract}

During the last decade, numerous studies have attempted to demonstrate that an overt behavior pattern, designated as Type A, is related to the development of heart disease (see Friedman, 1969). Type A behavior is characterized by extreme levels of competitive achievement striving, time urgency, and aggressiveness (Glass, 1977). In contrast, Type B, a non-coronary-prone behavior, is defined as the relative absence of Type A characteristics (Glass, 1977).

Adults are classified as one of the two types by means of either a standardized clinical interview (Friedman, 1969) or the Jenkins Activity Survey for Health Predictions (JAS), a 54-item questionnaire (Jenkins, Zyanski, \& Rosenman, 1971). A modified edition of the JAS has been used to classify collegeaged individuals (Krantz, Glass, \& Snyder, 1974), and the Matthews Youth Test for Health (MYTHForm O) has been used to classify children (Matthews \& Angulo, 1980). Furthermore, on the basis of the results of a 2-year study, Haynes, Feinleib, and Kannel (1980) concluded that Type A behavior operates independently of standard coronary risk factors such as age, cholesterol, and systolic blood pressure.

All of the Type A characteristics are seen as mechanisms by which the individual attempts to maintain control over the surrounding environment. Any situation that is perceived by the individual as a

J. L. Tramill's mailing address is: Department of Instructional Services, Wichita State University, Wichita, Kansas 67208. That of P. J. Kleinhammer-Tramill is: Department of Special Education, Associated Colleges of Central Kansas, McPherson, Kansas 67460. And that of S. F. Davis, C. S. Parks, and D. Alexander is: Department of Psychology, Emporia State University, Emporia, Kansas 66801 . threat to his/her control results in an intensification of these mechanisms (Glass, 1977). Moreover, Glass demonstrated that Type $\mathbf{A}$ individuals show greater reactions than do Type Bs to uncontrollable events that are very salient, whereas the opposite is true for events of very low salience.

Likewise, Type A individuals have been shown to reliably rate themselves as being more helpless and presumably more threatened by lack of control in high-stress/no-escape situations than in high-stress/ escape situations (Krantz et al., 1974). Similar results have been found with male children who have been classified as Type A with the aid of the MYTHForm O (Matthews, 1979).

One of the three main characteristics of the Type A personality is a strong sense of time urgency. For example, Glass, Snyder, and Hollis (1974) demonstrated that Type A individuals displayed greater impairment on a task requiring a response delay. Likewise, Burnam, Pennebaker, and Glass (1975) found that Type $\mathbf{A}$ individuals continually judged the lapse of 1 min sooner than did Type B individuals.

Elevated levels of aggressiveness have also been shown to be characteristic of Type $A$ adults and children. For example, such adults were shown to be significantly more aggressive than Type Bs when provoked by an annoying confederate or by a frustrating task (Carver \& Glass, 1978). Likewise, Matthews and Angulo (1980), in the process of developing the MYTH-Form O, found more aggressive behavior in Type A than in Type B male children.

Elements of competitive achievement striving have also been reported in numerous studies. Type $\mathbf{A}$ individuals have been shown to work at a task at near- 
maximum capacity, regardless of the presence or absence of a time deadline, whereas Type Bs exacted more effort only when an explicit deadline was evident (Burnam et al., 1975). To continue a tiring but challenging task, Type $\mathbf{A}$ individuals have repeatedly suppressed fatigue and performed closer to their endurance levels than have Type Bs (Carver, Coleman, \& Glass, 1976). Type As not only suppress fatigue more than do Type Bs, but they also are less likely to report physical symptoms of fatigue (Weidner \& Matthews, 1978). A possible explanation of this suppression has been suggested by Matthews and Brunson (1979). These investigators demonstrated that, in a dual task, Type As focused more on the actual task and less on the peripheral aspects than did Type Bs. This tendency of giving little attention to peripheral aspects of the situation would appear to be consistent with the Type As' denial of physical symptoms of fatigue.

Given this composite pattern of behaviors, it is clear that the Type A individual can be viewed as attempting to maintain control over his/her environment in a variety of ways. In view of this, it might be anticipated that uncontrollable forces or events would be viewed as stressful and/or anxiety producing by the Type $A$ individual. Hence, it would appear reasonable to predict that Type $A$ individuals would display higher scores on an anxiety scale, such as the Taylor Manifest Anxiety Scale (TMAS), than would Type B individuals. Certainly, one's death would potentially fall into the "uncontrollable" category. Therefore, a prediction of higher scores on a death anxiety survey [e.g., Death Anxiety Scale (DAS), Templer, 1970] by Type A than by Type B personalities would also appear reasonable. The present study was designed to investigate these predicted relationships.

\section{METHOD}

\section{Subjects}

The subjects were 123 college students (56 males, 67 females) enrolled in undergraduate courses at Wichita State University.

\section{Apparatus}

The modified JAS (see Krantz et al., 1974), the unidimensional short form of the TMAS (see Hicks, Ostle, \& Pellegrini, 1980), and the DAS (Templer, 1970) were employed as testing instruments. The unidimensional short form of the TMAS is a 20-item, true-false questionnaire that has been shown (Hicks et al., 1980) to have high test-retest $(r=.88)$ reliability. The modified JAS is a 21 -item, multiple-choice questionnaire having a normative mean of 8 and a standard deviation of 4. Hence, scores of 9-11 (+1 SD) would represent individuals with some Type $A$ tendencies, and scores of 12 and above ( $+2 \mathrm{SD}$ ) would reflect pronounced Type A characteristics. Conversely, scores of 5-7 ( -1 SD) would reflect individuals with some Type $B$ characteristics, and scores of $0-4$ ( -2 SD) would characterize strong Type B personalities. The DAS has 15 true-false items and has a test-retest reliability of .83 (Templer, 1970).

\section{Procedure}

Testing took place during a regular classroom session. The testing instruments were combined into a booklet and were to be selfadministered. Hence, other than instructions about the distribution and collection of the booklets and answer sheets, explicit instructions were not provided by the investigator.

\section{RESULTS AND DISCUSSION}

Prior to statistical analysis of the TMAS and DAS scores, the subjects were categorized by gender (male vs. female) and personality type (A+, $\mathrm{A}-, \mathrm{B}-$, and $B+)$. The following score ranges on the JAS were employed to determine the personality type classification: Type $\mathrm{A}+=12$ and above, Type $\mathrm{A}-=$ 9-11, Type $B-=5-7$, and Type $B+=0-4$.

Mean TMAS scores by gender and personality type are shown in Table 1. As can be seen from Table 1, females had a higher mean TMAS score than did males and Type A+ personalities had higher TMAS scores than did the other personality types. This pattern of results was corroborated by the analysis of variance of the TMAS scores, which yielded significance for the gender $[F(1,115)=34.89, p<.01]$, personality type $[F(3,115)=13.99, p<.01]$, and gender $\times$ personality type interaction $[F(3,115)=$ $2.82, p<.04]$ effects. The significant interaction was further probed through the use of the Newman-Keuls procedure. These tests indicated that Type $\mathrm{A}+$ males had significantly $(p<.01)$ higher TMAS scores than did the three other male personality types, which did not differ reliably from each other. Female Types A+ and $A$ - did not differ reliably from each other, but did display significantly $(p<.01)$ higher TMAS scores than did Types B - and B+, which did not differ reliably from each other.

Mean DAS scores by gender and personality type are shown in Table 2. As with the TMAS scores, it can be seen that females had a higher DAS mean than

Table 1

Mean TMAS Scores by Gender and Personality Type

\begin{tabular}{|c|c|c|c|c|c|c|c|c|c|c|}
\hline & \multicolumn{10}{|c|}{ Personality Type } \\
\hline & $A+$ & $\mathrm{n}$ & A- & $\mathbf{n}$ & B- & $\mathrm{n}$ & $\mathrm{B}+$ & $\mathrm{n}$ & & $\mathrm{n}$ \\
\hline Gender $\begin{array}{l}\text { Male } \\
\text { Female }\end{array}$ & $\begin{array}{r}8.39 \\
11.59\end{array}$ & $\begin{array}{l}18 \\
17\end{array}$ & $\begin{array}{l}4.23 \\
9.63\end{array}$ & $\begin{array}{l}13 \\
19\end{array}$ & $\begin{array}{l}5.64 \\
7.53\end{array}$ & $\begin{array}{l}11 \\
15\end{array}$ & $\begin{array}{l}5.00 \\
6.50\end{array}$ & $\begin{array}{l}14 \\
16\end{array}$ & $\begin{array}{l}6.04 \\
8.91\end{array}$ & $\begin{array}{l}56 \\
67\end{array}$ \\
\hline Composite Scores & 9.94 & 35 & 7.44 & 32 & 6.73 & 26 & 5.80 & 30 & & \\
\hline
\end{tabular}


Table 2

Mean DAS Scores by Gender and Personality Type

\begin{tabular}{llccccccccc}
\hline & \multicolumn{10}{c}{ Personality Type } \\
\cline { 2 - 11 } & $\mathrm{A}+$ & $\mathrm{n}$ & $\mathrm{A}-$ & $\mathrm{n}$ & $\mathrm{B}-$ & $\mathrm{n}$ & $\mathrm{B}+$ & $\mathrm{n}$ & & $\mathrm{n}$ \\
\hline \multirow{2}{*}{ Gender Male } & 6.67 & 18 & 5.38 & 13 & 6.09 & 11 & 4.86 & 14 & 5.80 & 56 \\
Female & 9.65 & 17 & 7.68 & 19 & 7.33 & 15 & 6.50 & 16 & 7.82 & 67 \\
Composite Scores & 8.11 & 35 & 6.75 & 32 & 6.81 & 26 & 5.73 & 30 & & \\
\hline
\end{tabular}

did males and that Type $\mathbf{A}+$ personalities produced the highest mean DAS score. Analysis of variance of the DAS scores yielded significance for the gender $[F(1,115)=19.64, p<.01]$ and personality type $[F(3,115)=5.06, p<.01]$ factors. Subsequent investigation (Newman-Keuls procedure) of the significant personality type factor indicated that Type A+ subjects had significantly $(p<.01)$ higher DAS scores than did the A-, B-, and B + subjects, which did not differ reliably from each other.

That higher DAS scores were shown by Type A+ individuals is certainly in accord with the initial prediction that this personality type would be associated with a higher fear of death. This finding suggests that this potentially uncontrollable event does create a considerable amount of anxiety in pronounced Type A males and females.

Similarly, significantly higher TMAS scores were clearly associated with Type A, rather than Type B, personalities. Yet, it is interesting to note that this relationship did differ slightly for males and females. More specifically, only Type A + males displayed significantly higher TMAS scores than Types $\mathrm{A}-$, $\mathrm{B}-$, and $\mathrm{B}+$ males, whereas both Types A+ and A - females had significantly higher TMAS scores than did Types B - and B + females. Thus, it would appear that, generally speaking, higher levels of anxiety may be associated with Type $A$ - females than with Type A - males.

Because similar results had been reported previously by Davis, Martin, Wilee, and Yoorhees (1978), Templer, Lester, and Ruff (1974), and Tramill, Davis, Bremer, Dudeck, and Elsbury (1982), the finding that females had significantly higher DAS scores than did males was not unexpected. Likewise, the finding that females had significantly higher TMAS scores than did males is in agreement with data reported by Tramill et al. (1982). Also in agreement with the Tramill et al. data was the finding that DAS and TMAS scores in the present study were significantly correlated $[\mathrm{r}(122)=.52, \mathrm{p}<.01]$.

\section{REFERENCES}

Burnam, M. A., Pennebaker, J. W., \& Glass, D. C. Time consciousness, achievement striving, and the Type A coronaryprone behavior pattern. Journal of Abnormal Psychology, 1975, 84, 76-79.
Carver, C. S., Coleman, A. E., \& Glass, D. C. The coronaryprone behavior pattern and the suppression of fatigue on a treadmill test. Journal of Personality and Social Psychology, 1976, 33, 460-466.

Carver, C. S., \& Glass, D. C. Coronary-prone behavior pattern and interpersonal aggression. Journal of Personality and Social Psychology, 1978, 36, 361-366.

Davis, S. F., Martin, D. A., Wilee, C. T., \& Voorhees, J. W. Relationship of fear of death and level of self-esteem in college students. Psychological Reports, 1978, 42, 419-422.

Friedman, M. Pathogenesis of coronary artery disease. New York: McGraw-Hill, 1969.

GLAss, D. C. Behavior patterns, stress, and coronary disease. Hillsdale, N.J: Erlbaum, 1977.

Glass, D. C., Snyder, M. L., \& Hollis, J. F. Time urgency and the Type A coronary-prone behavior pattern. Journal of Applied Social Psychology, 1974, 4, 125-140.

Haynes, S. G., Feinleib, M., \& Kannel, W. B. The relationship of psychosocial factors to coronary heart disease in the Framingham Study: III. Eight-year incidence of coronary heart disease. American Journal of Epidemiology, 1980, 111, 37-58.

Hicks, R. A., Ostre, J. R., \& Pellegrini, R. J. A unidimensional short form of the TMAS. Bulletin of the Psychonomic Society, 1980, 16, 447-448.

Jenkins, C. D., Zyanski, S. J., \& Rosenman, R. H. Progress toward validation of a computer-scored test for the Type A coronary-prone behavior pattern. Psychosomatic Medicine, 1971, 33, 193-202.

Krantz, D. S., Glass, D. C., \& Snyder, M. L. Helplessness, stress level, and the coronary-prone behavior pattern. Journal of Experimental Social Psychology, 1974, 10, 284-300.

Matthews, K. A. Efforts to control by children and adults with the Type A coronary-prone behavior pattern. Child Development, 1979, 50, 842-847.

Matthews, K. A., \& Angulo, J. Measurement of the Type A behavior pattern in children: Assessment of children's competitiveness, impatience-anger, and aggression. Child Development, 1980, 51, 466-475.

Matthews, K. A., \& Brunson, B. I. Allocation of attention and the Type A coronary-prone behavior pattern. Journal of Personality and Social Psychology, 1979, 37, 2081-2090.

Temple R, D. I. The construction and validation of a Death Anxiety Scale. Journal of General Psychology, 1970, 82, 165-177.

Templen, D. I., Lester, D., \& RuFF, C. F. Fear of death and femininity. Psychological Reports, 1974, 35, 530.

Tramill, J. L., Davis, S. F., Bremer, S., Dudeck, M. M., \& Elsbury, D. L. A proposed relationship between the unidimensional short form of the TMAS and the DAS: The effect of embedding vs. separate administration. Bulletin of the Psychonomic Society, 1982, 19, 209-211.

Weidner, G., \& Matthews, K. A. Reported physical symptoms elicited by unpredictable events and the Type A coronary-prone behavior pattern. Journal of Personality and Social Psychology, $1978,36,1213-1220$.

(Manuscript received for publication September 9, 1983.) 